\title{
PTEN inhibitor bisperoxovanadium protects oligodendrocytes and myelin and prevents neuronal atrophy in adult rats following cervical hemicontusive spinal cord injury
}

\author{
Chandler L. Walker, Ph.D. and Xiao-Ming Xu, M.D., Ph.D. \\ Spinal Cord and Brain Injury Research Group, Stark Neurosciences Research Institute, \\ Department of Neurological Surgery, and Department of Anatomical Sciences and Cell Biology, \\ Indiana University School of Medicine, 950 W. Walnut Street, R2 Building, Room 402, \\ Indianapolis, Indiana, 46202, United States of America
}

Chandler L. Walker: chalwalk@iupui.edu

\section{Abstract}

Cervical spinal cord injury (SCI) damages axons and motor neurons responsible for ipsilateral forelimb function and causes demyelination and oligodendrocyte death. Inhibition of the phosphatase and tensin homologue, PTEN, promotes neural cell survival, neuroprotection and regeneration in vivo and in vitro. PTEN inhibition can also promote oligodendrocyte-mediated myelination of axons in vitro likely through Akt activation. We recently demonstrated that acute treatment with phosphatase PTEN inhibitor, bisperoxovanadium (bpV)-pic reduced tissue damage, neuron death, and promoted functional recovery after cervical hemi-contusion SCI. Evidence suggests bpV can promote myelin stability; however, bpV effects on myelination and oligodendrocytes in contusive SCI models are unclear. We hypothesized that $\mathrm{bpV}$ could increase myelin around the injury site through sparing or remyelination, and that bpV treatment may promote increased numbers of oligodendrocytes. Using histological and immunofluorescence labeling, we found that $\mathrm{bpV}$ treatment promoted significant spared white matter $(30 \% ; p<0.01)$ and Luxol Fast Blue (LFB) ${ }^{+}$myelin area rostral (Veh: $0.56 \pm 0.01$ vs. bpV: $0.64 \pm 0.02 ; p<0.05$ ) and at the epicenter (Veh: $0.4175 \pm 0.03$ vs. bpV: $0.5400 \pm 0.03 ; p<0.05$ ). VLF oligodendrocytes were also significantly greater with bpV therapy $\left(109 \pm 5.3 \mathrm{vs}\right.$. Veh: $\left.77 \pm 2.7 / \mathrm{mm}^{2} ; p<0.01\right)$. In addition, bpV increased mean motor neuron soma area versus vehicle-treatment $(1.0 \pm 0.02 \mathrm{vs}$. Veh: $0.77 \pm 0.02)$ relative to Sham neuron size. This study provides key insight into additional cell and tissue effects that could contribute to $\mathrm{bpV}$-mediated functional recovery observed after contusive cervical SCI.

(C) 2014 Elsevier Ireland Ltd. All rights reserved.

*Corresponding author: Xiao-Ming Xu, M.D, Ph.D., Professor and Mari Hulman George Chair of Neurological Surgery, Scientific Director, Spinal Cord and Brain Injury Research Group, Stark Neurosciences Research Institute, Indiana University School of Medicine, 950 W Walnut St, R2 Building, Room 402, Indianapolis, IN 46202, Tel: (317) 274-1036, xu26@iupui.edu.

Publisher's Disclaimer: This is a PDF file of an unedited manuscript that has been accepted for publication. As a service to our customers we are providing this early version of the manuscript. The manuscript will undergo copyediting, typesetting, and review of the resulting proof before it is published in its final citable form. Please note that during the production process errors may be discovered which could affect the content, and all legal disclaimers that apply to the journal pertain. 


\section{Keywords}

bpV; PTEN; spinal cord injury; oligodendrocyte survival; neuron atrophy

\section{Introduction}

Traumatic spinal cord injury (SCI) physically damages long myelinated axon tracts of the spinal cord and instigates biochemical events that cause widespread cellular and tissue disruption around the site of primary injury. Within 24 hours following contusive SCI, gray matter tissue and cells at the injury epicenter are destroyed due to trauma and necrosis [1]. Demyelination commences, distal segments of disrupted axons undergo Wallerian degeneration and such axonopathology promotes delayed apoptotic cell death of associated oligodendrocytes [2,3]. Clearance of debris by phagocytic macrophages follows fragmentation and degeneration of myelin and degenerated axons [4].

In the days thereafter, glial cells react, proliferate and migrate which increases the number of reactive astrocytes and microglia around the lesion. Oligodendrocytes, the myelinating cells of the central nervous system (CNS) and their precursors (OPCs) mobilize toward the lesion, but behave differently than other glia and are susceptible to death near the epicenter and distal to the lesion [5-7]. Thus, many myelinated axons and oligodendrocytes suffer damage and degeneration, interfering with proper signal conduction and associated functional ability. Though oligodendrocytes begin axonal remyelination in the weeks to months following injury, such myelination is incomplete and the prognosis for significantly improved function is poor [4]. Endogenous mechanisms for initiating and stabilizing axonal myelination may be diluted by pathological cellular stimulation resulting in an overall net loss of myelinating cells, axons, and reduction in any remyelination effort.

Phosphatidylinositol-3-kinase (PI3K)/Akt signal transduction is important for oligodendrocyte differentiation, maintenance and stability of myelin, and cell survival [812]. We recently demonstrated that acute treatment of the small molecule, bisperoxovanadium (bpV[pic]), promoted reduced lesion and cavity formation, improved neural survival, and positively affected Akt and mammalian target of rapamycin (mTOR) activity through inhibition of the lipid phosphatase and tensin homologue (PTEN) as a potential mechanism of its action [13].

PTEN is highly expressed in penumbral oligodendrocytes following SCI, and upregulation of PI3K/Akt/mTOR signaling promotes oligodendrocyte lineage cell survival and myelination activity [14-18]. In this study, we hypothesized that bpV promotes sparing of oligodendrocytes around the lesion and protects myelination of associated axons following cervical SCI. Since bpV enhanced forelimb functional recovery and oligodendrocyte protection in the ventrolateral funiculus (VLF), an important region for rat locomotor ability, we examined whether bpV have an effect on protection/proliferation of oligodendrocytes in this region due to its anatomical and functional importance [19-21].

We also anticipated that bpV may have a protective effect on neuronal atrophy as compared to the non-treated controls. Our previous studies showed considerable autophagosome 
aggregation in cervical motor neurons following injury, and this activity may promote atrophy of surviving motor neurons in the injury penumbra. As this aggregation was reversed by $\mathrm{bpV}$ treatment, $\mathrm{bpV}$ could directly reduce potential neuronal atrophy observed after SCI [13]. In summary, this study aimed to investigate bpV's effects on oligodendrocyte survival, myelin sparing, and motoneuron atrophy after cervical contusive SCI.

\section{Materials and Methods}

\section{Cervical hemi-contusive SCI}

Adult female Sprague-Dawley rats $(200-250 \mathrm{~g}$, Harlan) $(\mathrm{n}=19)$ were randomly assigned to either sham surgery $(n=3)$, vehicle (saline)-treatment $(n=8)$, or bpV treatment $(n=8)$. The animals were anaesthetized intraperitoneally (IP) with ketamine $(87 \mathrm{mg} / \mathrm{kg}$ )/xylazine (12 $\mathrm{mg} / \mathrm{kg}$ ), and sham surgery or unilateral cervical SCI was performed as modified from Gensel et al [22]. The NYU/MASCIS Impactor ( $2.5 \mathrm{~mm}$ tip diameter, $10 \mathrm{~g}$ weight, dropped from a height of $12.5 \mathrm{~mm}$ ) was used to produce a moderate unilateral injury of the exposed spinal cord $[22,23]$. The animals then received a subcutaneous injection of $5 \mathrm{~mL} 0.9 \%$ saline for hydration and were placed in temperature-controlled housing overnight. All surgical and animal handling procedures were performed as approved under the Guide for the Care and Use of Laboratory Animals (National Research Council) and the Guidelines of the Indiana University School of Medicine Institutional Animal Care and Use Committee.

\section{Bisperoxovanadium treatment}

Two sets of rats were randomly designated for treatment with $\mathrm{bpV}(\mathrm{pic})(n=8)$ (Enzo Life Sciences) or vehicle $(n=8)$ with dosing modified from previous publication [24]. After cervical hemi-SCI, animals either received an immediate IP injection of $200 \mu \mathrm{g} / \mathrm{kg} \mathrm{bpV(pic)}$ in $0.9 \%$ saline or vehicle ( $0.9 \%$ saline). A third group served as a surgical control group (sham) and was also injected with vehicle according the prescribed dosing schedule $(n=3)$. Animals received a second dose of vehicle or bpV(pic) at 2 hours post-injury, and twice daily for 7 days $(400 \mu \mathrm{g} / \mathrm{kg} / \mathrm{d})$.

\section{Histological analysis}

Six weeks post-injury, tissue was collected and processed as previously published [25]. In brief, a $10 \mathrm{~mm}$ cervical spinal cord segment including the injury epicenter was extracted and cryo-sectioned transversely at $20 \mu \mathrm{m}$ thickness on Superfrost Plus slides (Fisher Scientific). Tissue was stained using cresyl violet acetate stain with eosin counterstaining (CVE) for tissue lesion/sparing assessment. Serial sections with an interval of $0.5 \mathrm{~mm}$ along the length of the cord were used for assessing spared white matter. Three to four sections of tissue at the epicenter, and $2 \mathrm{~mm}$ rostral and caudal from each groups were selected and stained with Luxol Fast Blue (LFB) for calculation of spared myelinated tissue. Spared white matter and myelination area were calculated using Image $\mathbf{J}(\mathrm{NIH})$.

\section{Immunofluorescence labeling of oligodendrocytes \& quantification}

Immunofluorescence labeling was performed as described in previous publication [13, 25]. Briefly, immunofluorescence labeling of oligodendrocytes $\sim 2 \mathrm{~mm}$ rostral and caudal to the epicenter was performed using different sets of samples from the same animal tissue as used 
for cresyl violet and LFB staining. Cord segments were incubated with primary antibody mouse anti-CC1 (APC-7, 1:50; Calbiochem, Inc.), a marker for oligodendrocytes. The following day, the sections were incubated with rhodamine-conjugated goat anti-mouse antibody (1:200; Jackson ImmunoResearch Lab). Sections were coverslip mounted with Fluoromount G (Southern Fluoromount) combined with Hoechst 33342 (1:100) for nuclear staining. Pre-immune serum was used to confirm the specificity of the antibody. Images were obtained with epifluoresecence-equipped Olympus BX60 microscope.

Quantification of surviving oligodendrocytes was performed in sections surrounding the injury site. The VLF was selected as the region of interest due to the influence of C5 hemicontusion on this area, and it contains axons related to propriospinal transduction of motor signaling and limb coordination [20,21, 26, 27]. Three sections per animal with an interval of $500 \mu \mathrm{m}$ within $\sim 1.5-3.0 \mathrm{~mm}$ rostral to the injury epicenter were selected for analysis via methods modified from a previous report [7]. The VLF was anatomically approximated in tissue sections as described by Cote et al. [28]. A pie grid divided into 16 equal sections was superimposed over the tissue image, and the section highlighted in red in Figure $2 \mathrm{~A}$ (the $6^{\text {th }}$ section clockwise from the dorsal midline of the grid) was designated as the VLF region of interest for the given tissue section. The interface between the white and gray matter, the dorsal and ventral margins of the grid section, and the lateral margin of the cord in this region were outlined using Neurolucida software to demarcate the VLF area of interest. In designated areas of intact ventrolateral white matter rostral to the injury site, the VLF area was measured and $\mathrm{CC}^{+}$oligodendrocytes were quantified within this region using automation within Microbrightfield Neurolucida software. Only clearly identifiable $\mathrm{CC}^{+}$ cell soma co-labeled with nuclear stain were included for quantification. The data were represented as the number of oligodendrocytes per $\mathrm{mm}^{2}$.

\section{Assessment of penumbral motor neuron atrophy}

To address whether bpV has an effect on prevention of neuronal atrophy in surviving motor neurons around the site of injury, rat spinal sections in the sham, vehicle- and bpV-treated groups at 6 weeks post-SCI were examined. Motor neuron atrophy was measured by identifying 3 sections $400 \mu \mathrm{m}$ apart spanning from $\sim 1.5$ to $3.0 \mathrm{~mm}$ both rostral and caudal from the injury epicenter per animal. Motor neurons were defined as previously published [13]. In brief, large evenly stained neurons in the ventral horn with nucleus in plane were selected for all groups, and each was traced and area measured using ImageJ software. Sham rat motor neuron area was normalized to $100 \%$ (1.0) and mean Vehicle- and bpV-treated group measurements were displayed as percent change of the sham value. Approximately 40 motor neurons were measured per animal to obtain mean values for each group.

\section{Statistical analysis}

To determine significance between two groups, a two-tailed unpaired Student's t-test was used. Statistical significance between multiple groups was determined using a one-way ANOVA with Newman-Keuls post-hoc analysis. All statistical values were calculated using GraphPad Prism 5.0 software (GraphPad, Inc.), with a $p$ value $<0.05$ considered statistically significant. 


\section{Results}

At 6 weeks post-SCI, animals treated with bpV exhibited increased white matter $(p<0.05$; Fig. 1A \& D) and $\mathrm{LFB}^{+}$myelin around and at the injury epicenter ( $p<0.05$; Fig. 1B \& F) compared with vehicle-treated SCI rats (Fig. 1C \& E). Representative photomicrographs illustrate these effects in the ipsilateral cervical spinal cord. Since white matter and myelin were spared following $\mathrm{bpV}$ (pic) treatment, we investigated the survival of oligodendrocytes, which are important for myelination in the VLF. Oligodendrocyte soma co-labelled with $\mathrm{CC} 1$ and Hoechst nuclear stain in the VLF were quantified (Fig. 2B-C'). As shown in Fig. 2D \& E, and graphically in Fig. $2 \mathrm{~F}$, bpV significantly enhanced the number of $\mathrm{CC}^{+}$ oligodendrocytes in the VLF rostral to the injury epicenter. Furthermore, the soma area of ventral horn motor neurons were significantly larger $(\sim 25 \%)$ than saline-treated animals (Fig. 3A-C) and exhibited similar size and morphological appearance to sham-operated rats (Fig. 3C).

\section{Discussion}

Increased white matter and myelinated axons might result from general neuroprotective effects of bpV therapy, or alternatively, through bpV-mediated reparative processes [13]. As shown in this report, $\mathrm{bpV}$ facilitated increased chronic white matter and myelination sparing or repair (Fig. 1). The observed improvement in these parameters implicated a sparing or increase of adult myelinating oligodendrocytes, quantification of $\mathrm{CC}^{+}$oligodendrocytes was performed $\sim 1.5$ to $3 \mathrm{~mm}$ rostral, the distance at which significant neuron and tissue sparing was observed within the VLF, an axon tract which served as an indicator of the spread of white matter damage, and is involved in forelimb motor control and locomotor coordination via propriospinal interenlargement connections [21, 22, 27]. Following cervical hemi-contusive SCI, the lesion occupies considerable portions of the lateral and ventrolateral funiculi at the epicenter and tapers when distances increase rostral and caudal to the epicenter. As lesion is reduced, the VLF is spared at distances near the epicenter allowing the examination of VLF at approximately $2 \mathrm{~mm}$ rostral \& caudal to the epicenter as a region of interest to assess $\mathrm{bpV}$ treatment effect [13]. We observed a significant increase in oligodendrocytes within the VLF at these regions following bpV treatment compared to vehicle-treated animals (Fig. 2D-F). As such, enhanced oligodendrocyte support or remyelination of axons may have influenced the integrity and functionality of white matter witnessed following treatment. Alternatively, reduced spread of secondary damage and inflammation induced by bpV may have spared injury to all these cord structures, contributing to overall neuroprotection. It has been shown that $\mathrm{bpV}$ compounds can also enhance proliferation of oligodendrocyte precursors [29]; therefore bpV may have enhanced proliferation of oligodendrocyte precursors resulting in the increased quantity of $\mathrm{CC}^{+}$ oligodendrocytes observed following treatment. A combination of these effects is possible, and further studies are needed to clarify specific influence of $\mathrm{bpV}$ on spared or newly formed oligodendrocytes following SCI.

Damaged or denervated neurons exhibit soma atrophy after axonal injury [30, 31]. We found that $\mathrm{bpV}$ either directly or indirectly ameliorated injury-induced reduction in soma size (Fig. 3A-C). The significant increase in soma size could be due to indirect reduction in spread of 
secondary damage and lesion size which could result in larger, more normal appearing neuron soma in tissue surrounding the injury site. However, loss of PTEN function has been shown to increase the size of neurons and brain tissue due to upregulated activation of translational processes mediated by the Akt/mTOR signaling axis, adding a potentially signal-mediated mechanistic effect of bpV effect on neural cell body size [32, 33].

Administration of bpV may have stimulated protein synthesis and growth of neurons through PTEN inhibition and subsequent upregulation of mTOR activity indicating a more active role for $\mathrm{bpV}$ in modulating cell soma size. Interestingly, neuron hypertrophy mediated by PTEN loss has been shown to be independent of downstream ribosomal protein S6 Kinase 1 (S6K1), suggesting other pathways may be involved in this process in addition to PI3K/Akt/mTOR signaling [34]. Further biochemical and cellular analysis are required to better understand the exact processes by which bpV may mediate this effect following injury.

In conclusion, we now know that systemic acute bpV treatment affords extensive neuroprotection including lesion reduction, white matter and myelin sparing, and reduction of cell death. Our current and previous findings also suggest cellular protection by bpV may proceed through downregulation of autophagy and apoptosis. Due to the complexity of signal interactions and positive and negative feedback mechanisms, elucidating specific cellular and molecular effects of chemical therapeutics is difficult. Despite these obstacles, this study furthers our knowledge of bpV's action as a therapeutic compound, and it is clear that it likely exhibits differential cell-specific effects while still promoting an overall neuroprotective result, reducing cell death mechanisms, and promoting functional recovery following cervical hemicontusion SCI. Further studies will elucidate more specific details of Akt/mTOR effects of bpV therapy on oligodendrocytes, and other cell types; however, this report stands as additional foundational evidence for the efficacy and potential mechanisms of the use of bpV compounds as an acute treatment following traumatic cervical SCI.

\section{Acknowledgments}

This work was supported by National Institutes of Health (NIH/NINDS R01 NS059622, NS050243, NS073636 to XMX, and F31NS 071863 to CLW), the Indiana Spinal Cord and Brain Injury Research Funds, the Mari Hulman George Endowment Funds. We also appreciate the use of the Core facility of the Spinal Cord and Brain Injury Research Group/Stark Neurosciences Research Institute at Indiana University.

\section{References}

1. Ek CJ, Habgood MD, Callaway JK, Dennis R, Dziegielewska KM, Johansson PA, Potter A, Wheaton B, Saunders NR. Spatio-temporal progression of grey and white matter damage following contusion injury in rat spinal cord. PLoS One. 2010; 5:e12021. [PubMed: 20711496]

2. Norenberg MD, Smith J, Marcillo A. The pathology of human spinal cord injury: defining the problems. J. Neurotrauma. 2004; 21:429-440. [PubMed: 15115592]

3. Warden P, Bamber NI, Li H, Esposito A, Ahmad KA, Hsu CY, Xu XM. Delayed glial cell death following Wallerian degeneration in white matter tracts after spinal cord dorsal column cordotomy in adult rats. Exp. Neurol. 2001; 168:213-224. [PubMed: 11259109]

4. Totoiu MO, Keirstead HS. Spinal cord injury is accompanied by chronic progressive demyelination. J. Comp. Neurol. 2005; 486:373-383. [PubMed: 15846782] 
5. Crowe MJ, Bresnahan JC, Shuman SL, Masters JN, Beattie MS. Apoptosis and delayed degeneration after spinal cord injury in rats and monkeys. Nat. Med. 1997; 3:73-76. [PubMed: 8986744]

6. Liu XZ, Xu XM, Hu R, Du C, McDonald JW, Dong HX, Wu YJ, Fan GS, Jacquin MF, Hsu CY, Choi DW. Neuronal and glial apoptosis after traumatic spinal cord injury. J. Neurosci. 1997; 17:5395-5406. [PubMed: 9204923]

7. Whitaker CM, Beaumont E, Wells MJ, Magnuson DS, Hetman M, Onifer SM. Rolipram attenuates acute oligodendrocyte death in the adult rat ventrolateral funiculus following contusive cervical spinal cord injury. Neurosci. Lett. 2008; 438:200-204. [PubMed: 18455876]

8. Chuenkova MV, Furnari FB, Cavenee WK, Pereira MA. Trypanosoma cruzi trans-sialidase: a potent and specific survival factor for human Schwann cells by means of phosphatidylinositol 3-kinase/Akt signaling. Proc. Natl. Acad. Sci. U S A. 2001; 98:9936-9941. [PubMed: 11481434]

9. Harrington EP, Zhao C, Fancy SP, Kaing S, Franklin RJ, Rowitch DH. Oligodendrocyte PTEN is required for myelin and axonal integrity, not remyelination. Ann. Neurol. 2010; 68:703-716. [PubMed: 20853437]

10. Liu S, Stewart TJ, Howard MJ, Chakrabortty S, Holekamp TF, McDonald JW. Embryonic stem cells differentiate into oligodendrocytes and myelinate in culture and after spinal cord transplantation. Proc. Natl. Acad. Sci. USA. 2001; 97:6126-6131. [PubMed: 10823956]

11. Tyler WA, Gangoli N, Gokina P, Kim HA, Covey M, Levison SW, Wood TL. Activation of the mammalian target of rapamycin (mTOR) is essential for oligodendrocyte differentiation. J. Neurosci. 2009; 29:6367-6378. [PubMed: 19439614]

12. Ogata T, Iijima S, Hoshikawa S, Miura T, Yamamoto S, Oda H, Nakamura K, Tanaka S. Opposing extracellular signal-regulated kinase and Akt pathways control schwann cell myelination. J. Neurosci. 2004; 24:6724-6732. [PubMed: 15282275]

13. Walker CL, Walker MJ, Liu NK, Risberg EC, Gao X, Chen J, Xu XM. Systemic bisperoxovanadium activates Akt/mTOR, reduces autophagy, and enhances recovery following cervical spinal cord injury. PLoS One. 2012; 7:e30012. [PubMed: 22253859]

14. Flores AI, Narayanan SP, Morse EN, Shick HE, Yin X, Kidd G, Avila RL, Kirschner DA, Macklin WB. Constitutively active Akt induces enhanced myelination in the CNS. J. Neurosci. 2008; 28:7174-7183. [PubMed: 18614687]

15. Narayanan SP, Flores AI, Wang F, Macklin WB. Akt signals through the mammalian target of rapamycin pathway to regulate CNS myelination. J. Neurosci. 2009; 29:6860-6870. [PubMed: 19474313]

16. Slaets H, Dumont D, Vanderlocht J, Noben JP, Leprince P, Robben J, Hendriks J, Stinissen P, Hellings N. Leukemia inhibitory factor induces an antiapoptotic response in oligodendrocytes through Akt-phosphorylation and up-regulation of 14-3-3. Proteomics. 2008; 8:1237-1247. [PubMed: 18338825]

17. Wang XQ, Yao RQ, Liu X, Huang JJ, Qi DS, Yang LH. Quercetin protects oligodendrocyte precursor cells from oxygen/glucose deprivation injury in vitro via the activation of the PI3K/Akt signaling pathway. Brain Res. Bull. 2011; 86:277-284. [PubMed: 21803128]

18. Xu C, Lv L, Zheng G, Li B, Gao L, Sun Y. Neuregulin1beta1 protects oligodendrocyte progenitor cells from oxygen glucose deprivation injury induced apoptosis via ErbB4-dependent activation of PI3-kinase/Akt. Brain Res. 2012; 1467:104-112. [PubMed: 22659027]

19. Beaumont E, Whitaker CM, Burke DA, Hetman M, Onifer SM. Effects of rolipram on adult rat oligodendrocytes and functional recovery after contusive cervical spinal cord injury. Neurosci. 2009; 163:985-990.

20. Loy DN, Magnuson DS, Zhang YP, Onifer SM, Mills MD, Cao QL, Darnall JB, Fajardo LC, Burke DA, Whittemore SR. Functional redundancy of ventral spinal locomotor pathways. J. Neurosci. 2002; 22:315-323. [PubMed: 11756515]

21. Loy DN, Talbott JF, Onifer SM, Mills MD, Burke DA, Dennison JB, Fajardo LC, Magnuson DS, Whittemore SR. Both dorsal and ventral spinal cord pathways contribute to overground locomotion in the adult rat. Exp. Neurol. 2002; 177:575-580. [PubMed: 12429203] 
22. Gensel JC, Tovar CA, Hamers FP, Deibert RJ, Beattie MS, Bresnahan JC. Behavioral and histological characterization of unilateral cervical spinal cord contusion injury in rats. J. Neurotrauma. 2006; 23:36-54. [PubMed: 16430371]

23. Gruner JA. A monitored contusion model of spinal cord injury in the rat. J. Neurotrauma. 1992; 9:123-128. [PubMed: 1404425]

24. Zhang QG, Wu DN, Han D, Zhang GY. Critical role of PTEN in the coupling between PI3K/Akt and JNK1/2 signaling in ischemic brain injury. FEBS. Lett. 2007; 581:495-505. [PubMed: 17239858]

25. Liu NK, Zhang YP, Titsworth WL, Jiang X, Han S, Lu PH, Shields CB, Xu XM. A novel role of phospholipase A(2) in mediating spinal cord secondary injury. Ann. Neurol. 2006; 59:606-619. [PubMed: 16498630]

26. Giovanelli Barilari M, Kuypers HG. Propriospinal fibers interconnecting the spinal enlargements in the cat. Brain Res. 1969; 14:321-330. [PubMed: 5794910]

27. Sterling P, Kuypers HG. Anatomical organization of the brachial spinal cord of the cat. 3 . The propriospinal connections. Brain Res. 1968; 7:419-443. [PubMed: 5639606]

28. Cote MP, Detloff MR, Wade RE Jr, Lemay MA, Houle JD. Plasticity in ascending long propriospinal and descending supraspinal pathways in chronic cervical spinal cord injured rats. Frontiers in physiology. 2012; 3:330. [PubMed: 22934078]

29. De Paula ML, Cui QL, Hossain S, Antel J, Almazan G. The PTEN inhibitor bisperoxovanadium enhances myelination by amplifying IGF-1 signaling in rat and human oligodendrocyte progenitors. Glia. 2014; 62:64-77. [PubMed: 24166839]

30. Kobayashi NR, Fan DP, Giehl KM, Bedard AM, Wiegand SJ, Tetzlaff W. BDNF and NT-4/5 prevent atrophy of rat rubrospinal neurons after cervical axotomy, stimulate GAP-43 and Talpha1tubulin mRNA expression, and promote axonal regeneration. J. Neurosci. 1997; 17:9583-9595. [PubMed: 9391013]

31. Ma J, Novikov LN, Wiberg M, Kellerth JO. Delayed loss of spinal motoneurons after peripheral nerve injury in adult rats: a quantitative morphological study. Exp. Brain Res. 2001; 139:216-223. [PubMed: 11497064]

32. Eng C. PTEN: one gene, many syndromes. Hum. Mutat. 2003; 22:183-198. [PubMed: 12938083]

33. Fraser MM, Zhu X, Kwon CH, Uhlmann EJ, Gutmann DH, Baker SJ. Pten loss causes hypertrophy and increased proliferation of astrocytes in vivo. Cancer Res. 2004; 64:7773-7779. [PubMed: 15520182]

34. Chalhoub N, Kozma SC, Baker SJ. S6k1 is not required for Pten-deficient neuronal hypertrophy. Brain Res. 2006; 1100:32-41. [PubMed: 16777079] 


\section{Highlights}

- Rats treated with PTEN inhibitor bisperoxovanadium for cervical spinal cord injury.

- White matter, myelin, and ventrolateral funiculus oligodendrocytes were spared.

- Injury-induced neuronal soma atrophy was reversed by bisperoxovanadium. 
A
Spared White Matter

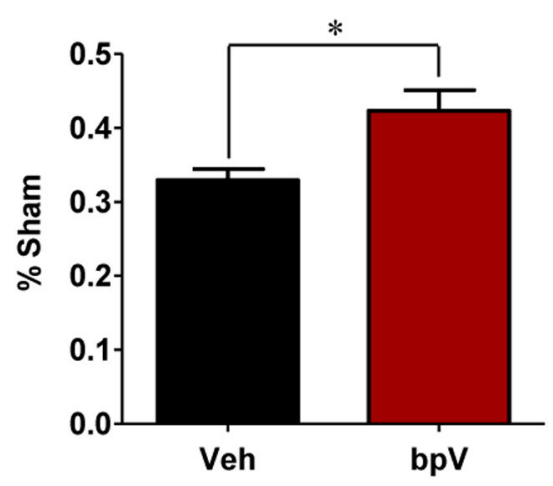

B Spared Myelinated White Matter

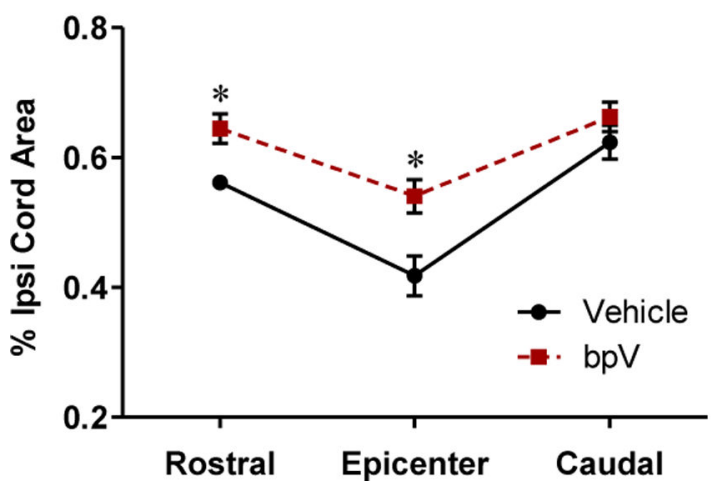

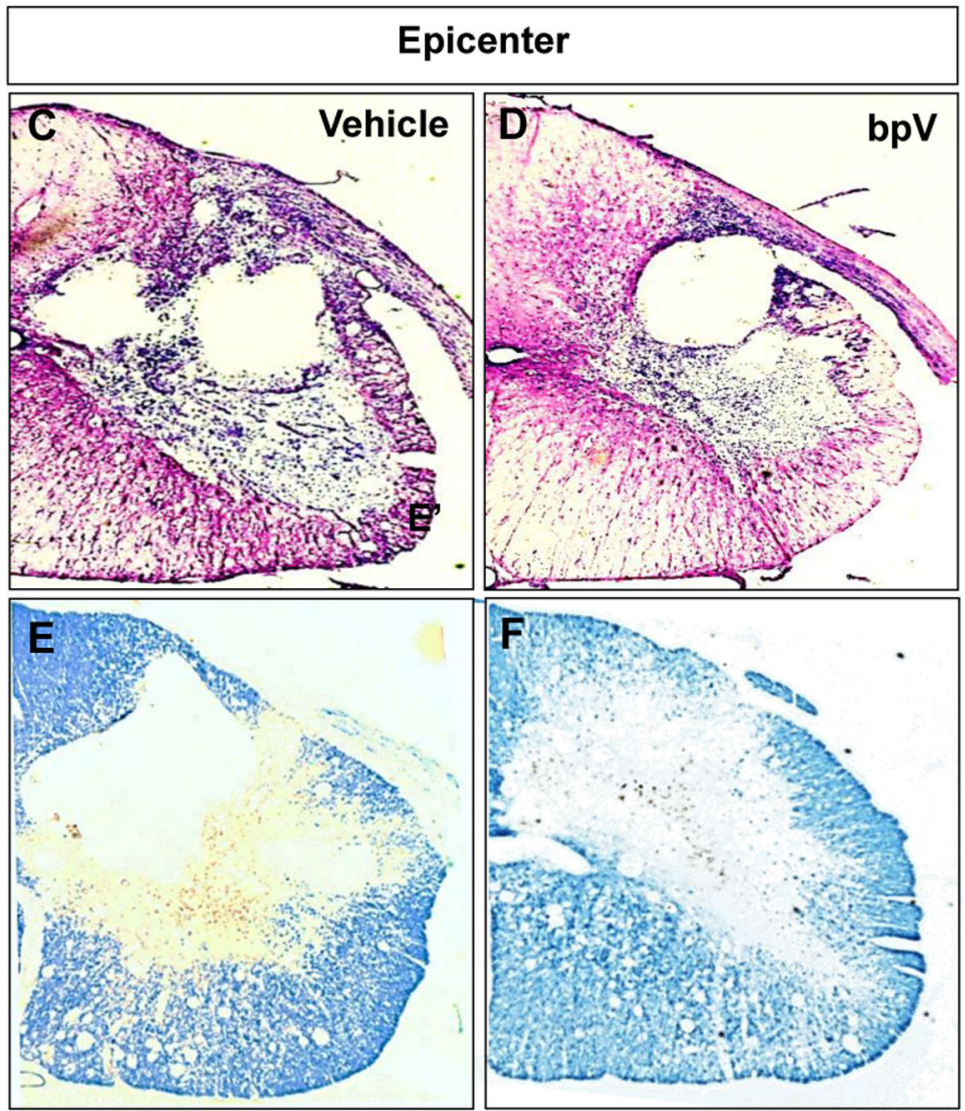

Figure 1. bpV promoted spared white matter and myelin in the ipsilateral cord following cervical hemicontusion SCI

A) Compared to saline (Veh)-treated rats, $\mathrm{bpV}$ significantly improved white matter sparing in the injured cervical spinal cord 6 weeks post-SCI $(p<0.05)$. B) Likewise, cervical hemiSCI induced myelin loss was significantly attenuated $2 \mathrm{~mm}$ rostral and at the epicentre of injury by bpV over the Vehicle-treatment group $(p<0.05)$. No significant difference was observed in LFB+ myelin area of the ipsilateral cord caudal to the epicenter. Representative micrographs of ipsilateral white matter (C, D) and myelination (E, F) are provided. Scale bar: $\mathrm{C}-\mathrm{F}=500 \mu \mathrm{m}$. 

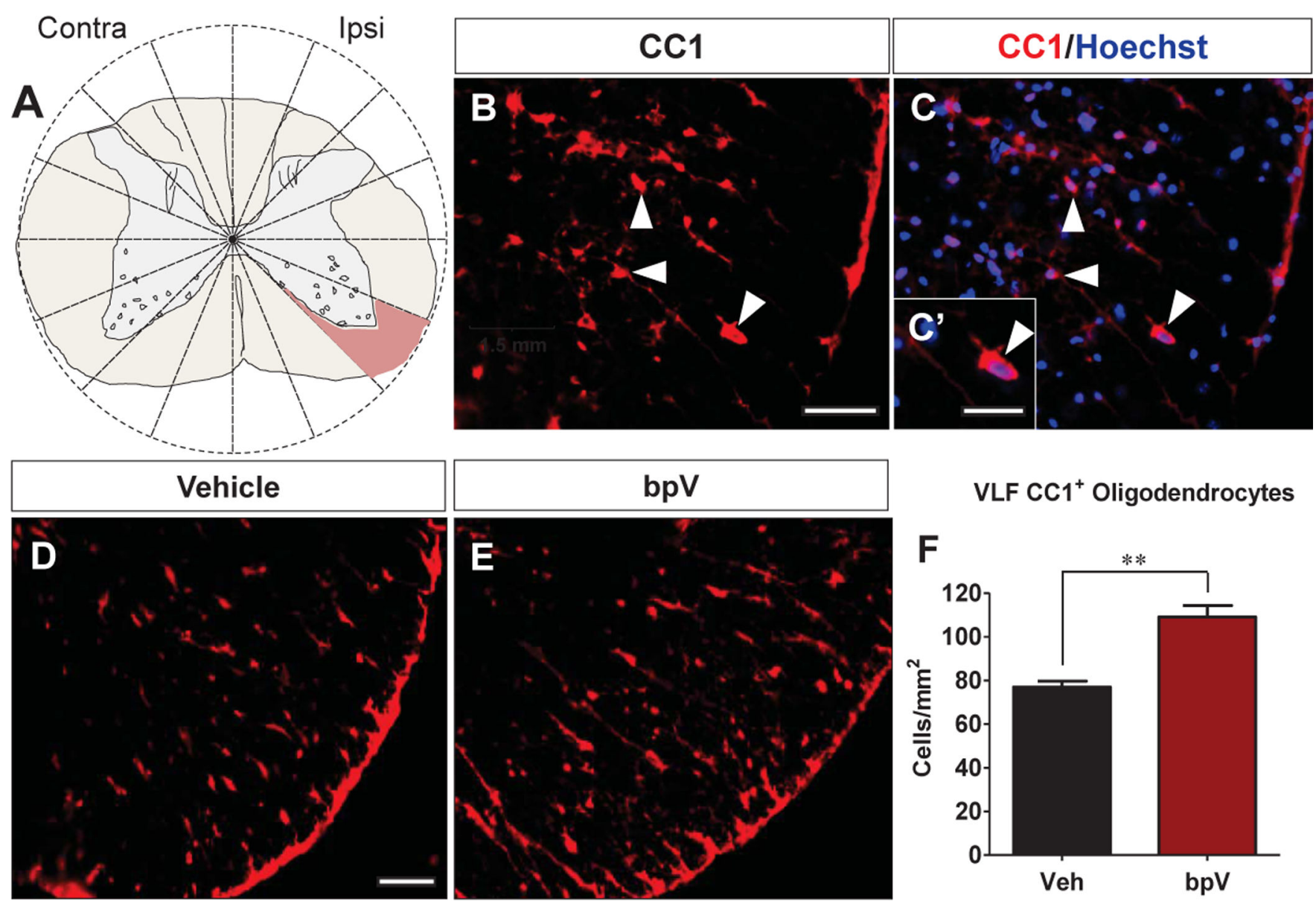

Figure 2. Injury-mediated reduction of $\mathrm{CC1}$ + oligodendrocytes in the VLF was reversed by bpV treatment

A) Schematic diagram for designating the VLF for $\mathrm{CC} 1+$ oligodendrocyte quantification per section. The area shaded in red was used the outline the VLF for further analysis. B - C') Oligodendrocyte soma exhibiting co-labeling with Hoechst 33342 and $\mathrm{CC} 1$ (white arrowheads) in the VLF. D - F) bpV treatment resulted in a greater quantity of oligodendrocytes in the ipsilateral VLF over Veh-treated rats following cervical hemicontusion SCI $(p<0.01)$. Scale bar: A $-\mathrm{C}=50 \mu \mathrm{m} ; \mathrm{C}^{\prime}=25 \mu \mathrm{m}$; D \& $\mathrm{E}=50 \mu \mathrm{m}$. 

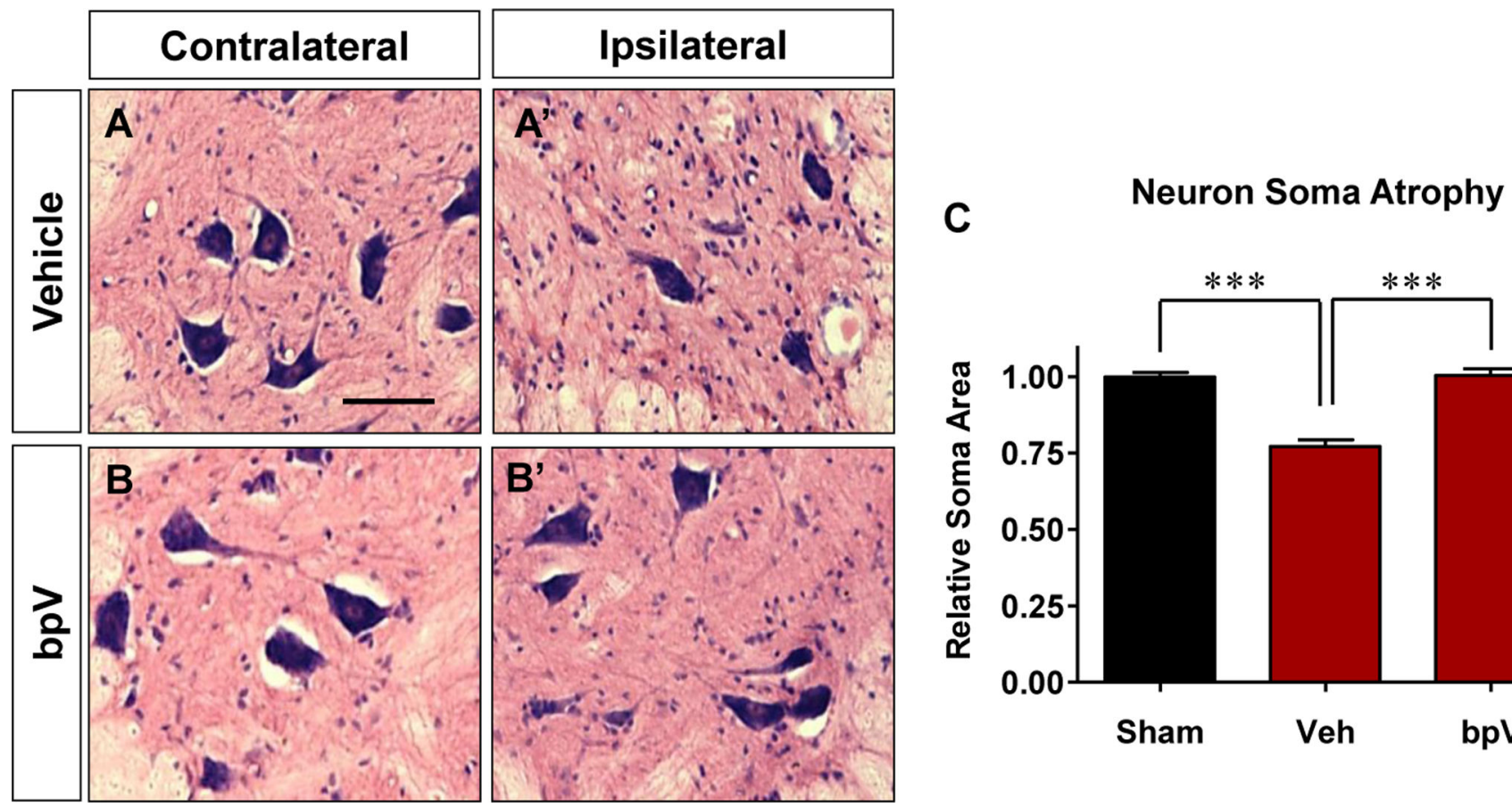

Figure 3. bpV treatment increased spared motor neuron soma size A - C) bpV treatment diminished atrophy of motor neuron soma rostral and caudal to the injury site $(p<0.001)$. C) The final average soma area for $\mathrm{bpV}$-treated rats was similar to the average for sham animals. Saline vehicle-treated rats exhibited an overall average atrophy of $\sim 20 \%$ ipsilateral neuron soma size at 6 weeks post-SCI. Scale bar: A - B' $=50$ $\mu \mathrm{m}$. 